\title{
Persistent organic pollutants distribution in lipoprotein fractions in relation to cardiovascular disease and cancer.
}

\author{
Stefan A Ljunggren, Ingela Helmfrid, Samira Salihovic, Bert van Bavel, Gun Wingren, Mats \\ Lindahl and Helen Karlsson
}

\section{Linköping University Post Print}

\section{Tweet}

N.B.: When citing this work, cite the original article.

Original Publication:

Stefan A Ljunggren, Ingela Helmfrid, Samira Salihovic, Bert van Bavel, Gun Wingren, Mats Lindahl and Helen Karlsson, Persistent organic pollutants distribution in lipoprotein fractions in relation to cardiovascular disease and cancer., 2014, Environment International, (65), 93-9. http://dx.doi.org/10.1016/j.envint.2013.12.017

Copyright: Elsevier

http://www.elsevier.com/

Postprint available at: Linköping University Electronic Press

http://urn.kb.se/resolve?urn=urn:nbn:se:liu:diva-104755 


\section{Persistent Organic Pollutants Distribution in Lipoprotein Fractions in Relation to Cardiovascular Disease and Cancer}

Stefan A. Ljunggren ${ }^{\mathrm{a}}$, Ingela Helmfrid ${ }^{\mathrm{b}}$, Samira Salihovic ${ }^{\mathrm{c}}$, Bert van Bavel ${ }^{\mathrm{c}}$, Gun Wingren ${ }^{\mathrm{a}}$, Mats Lindahl ${ }^{\mathrm{a}}$, Helen Karlsson ${ }^{\mathrm{b}, *}$

${ }^{a}$ Department of Clinical and Experimental Medicine, Linköping University, SE-58185

Linköping, Sweden ${ }^{\mathrm{b}}$ Occupational and Environmental Medicine, County Council of

Östergötland, Linköping University, SE-58185 Linköping, Sweden ${ }^{c}$ Man-Technology-

Environment (MTM) Research Centre, Örebro University, SE-70182 Örebro, Sweden

Email addresses:

stefan.ljunggren@liu.se

bert.vanbavel@oru.se

mats.lindahl@liu.se

ingela.helmfrid@lio.se

gun.wingren@liu.se

helen.m.karlsson@liu.se

samira.salihovic@oru.se

* Corresponding author:

Helen Karlsson

Occupational and Environmental Medicine

Linköping University Hospital

County Council of Östergötland

SE-581 85 Linkoping, SWEDEN

+46-101034414

Email; helen.m.karlsson@liu.se 


\section{Graphical Abstract}

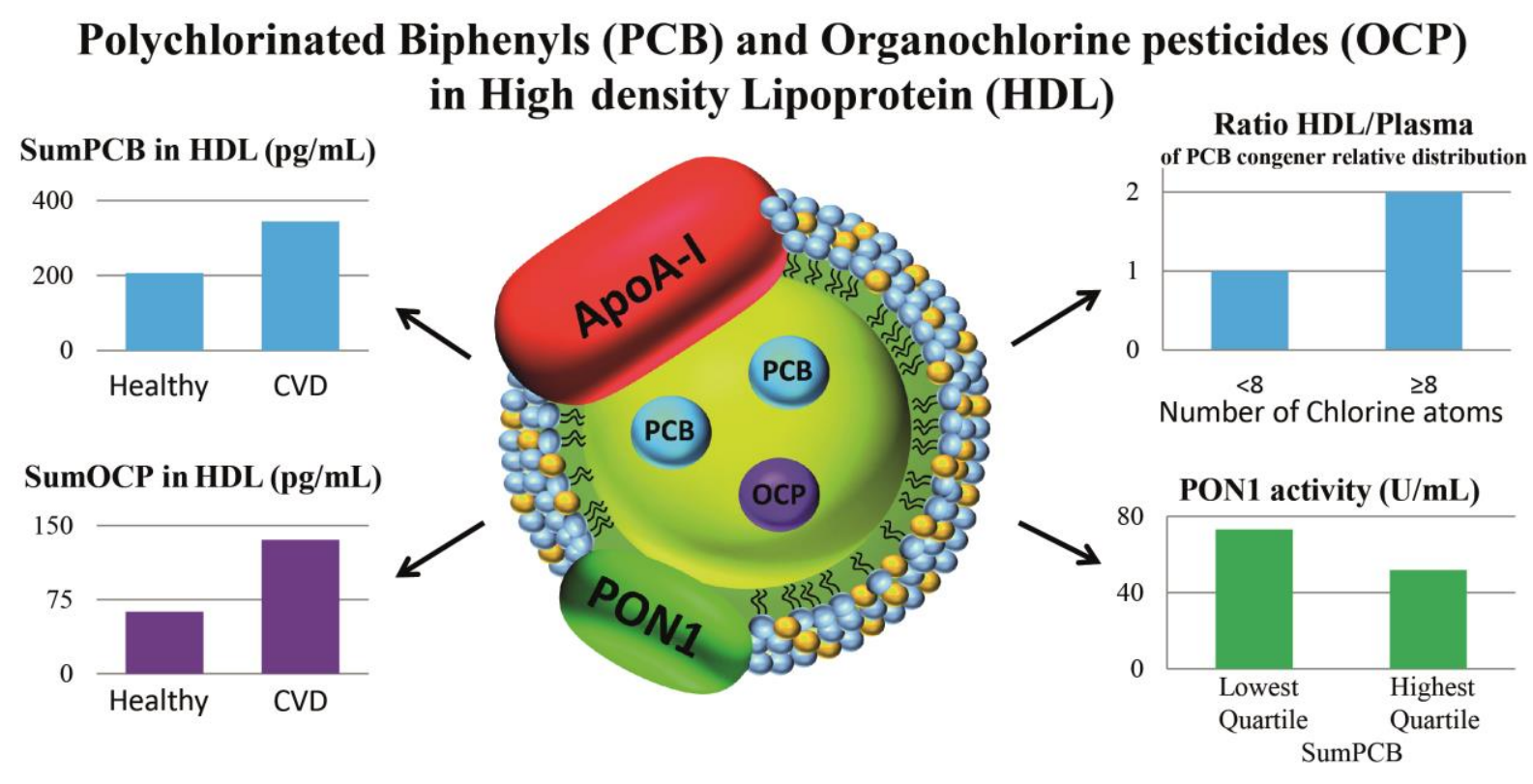

Left panels: Higher concentrations of PCBs and OCPs in HDL from subjects with CVD and cancer than healthy controls. Upper right panel: Enrichment of highly chlorinated PCB congeners in HDL. Lower right panel: Less activity of the HDL anti-oxidant enzyme PON1 in subjects with high PCB concentrations than in subjects with low PCB concentrations.

\section{Highlights}

Higher POP concentrations in subjects with CVD or cancer compared to healthy controls

Association between high PCB concentrations in HDL and CVD

Association between high PCB concentrations in LDL and cancer

PCB concentration and PON1 activity are inversely correlated in subjects with CVD 
Abbreviations:

AhR: Aryl hydrocarbon receptor

CVD : Cardiovascular disease

HCB - Hexachlorobenzene

HDL: High-density lipoprotein

HDL-C: HDL cholesterol

HRGC-HRMS - high resolution gas chromatography/high resolution mass spectrometry

LOD: Limit of detection

LDL: Low-density lipoprotein

LDL-C: LDL cholesterol

LDL/VLDL: Low-density lipoprotein/ Very low-density lipoprotein

OCDD - octachlorodibenzo-p-dioxin

OCP: Organochlorine pesticide

p,p'-DDE - 1,1-bis-(4-chlorophenyl)-2,2-dichloroethene

p,p'-DDT - 1,1,1-trichloro-2,2-bis(4-chlorophenyl)ethane

PBDE - Polybrominated diphenyl ether

PC: Principal Component

PCA: Principal component analysis

PCB: Polychlorinated biphenyl

PON1: Paraoxonase 1

POP: Persistent organic pollutant

sumPCB: Sum of PCB Congeners

VLDL: Very low-density lipoprotein 


\begin{abstract}
Persistent organic pollutants (POPs) are lipophilic environmental toxins that have been associated with cardiovascular disease (CVD) and cancer. The aim of this study was to investigate the concentrations of POPs in human high and low/very low-density lipoproteins (HDL and LDL/VLDL) and the possible association with CVD and cancer occurrence in individuals living in a contaminated area. Lipoproteins from 28 individuals ( 7 healthy controls, 8 subjects with cancer, 13 subjects with CVD) were isolated and the fraction-specific concentration of 20 different POPs was analyzed by high resolution gas chromatography/high resolution mass spectrometry. The activity of Paraoxonase 1 (PON1), an anti-oxidant in HDL, was determined in plasma of these 28 subjects and additional 50 subjects from the same area excluding diseases other than cancer or CVD. Fourteen polychlorinated biphenyls (PCBs) and three organochlorine pesticides were detected, and especially highly chlorinated PCBs were enriched in lipoproteins. Significantly higher concentrations of POPs were found among individuals with CVD or cancer compared to controls. Principal component analyses showed that POP concentrations in HDL were more associated with CVD, while POP concentrations in LDL/VLDL were more associated with cancer. PON1 activity was negatively correlated to sumPCB and a co-variation between decreased arylesterase-activity, increased PCB concentrations and CVD was found. This study shows that POPs are present in lipoproteins and were more abundant in individuals with CVD or cancer compared to healthy controls. The results also indicate that PCB exposure is accompanied by reduced PON1 activity that could impair the HDL function to protect against oxidation.
\end{abstract}

Keywords: Cancer, Cardiovascular disease, Lipoproteins, Paraoxonase-1, Persistent organic pollutants 


\section{Introduction}

Persistent organic pollutants (POPs) are a heterogeneous group of man-made chemicals, with a long half-life, that accumulate in fat tissues due to their lipophilic nature. POPs, as defined by the Stockholm Convention, hosted by the United Nations Environment Programme (www.unep.org), include polychlorinated biphenyls (PCBs), dioxins, organochlorine pesticides (OCPs) as well as polybrominated diphenyl ethers (PBDEs) (Wikoff et al 2012). Several studies have found associations between increased serum or plasma concentrations of POPs and an increased risk for negative health effects in the general population, including cardiovascular disease (CVD) (Lind et al. 2012; Sergeev and Carpenter 2010), diabetes (Færch et al. 2012; Lee et al. 2011) and cancer (Engel et al. 2007; Hardell et al. 2006). The causal association between POPs and cancer has however been questioned (Golden and Kimbrough 2009). In addition, some studies show that people living in industrial contaminated areas have higher concentrations of POPs in plasma compared to control populations (Hovander et al. 2006) and that people consuming locally produced food in contaminated areas have higher concentrations of POPs compared to people consuming locally produced food in non-contaminated areas (Donato et al. 2006; Langer et al. 2007).

Although banned for more than thirty years, PCBs still persist in the environment and in food sources such as fish, meat and dairy products (Diamond et al. 2010). The 209 different PCB congeners can either be coplanar or non-coplanar, depending on the positions of the chlorine atoms. The coplanar congeners resemble dioxins and these dioxin-like PCBs have been shown to activate the aryl hydrocarbon receptor (AhR) (Henry and DeVito 2003). The AhR affects different signaling pathways including the retinoic acid receptor, the estrogen receptor and nuclear factor $\kappa \mathrm{B}$ and may also have a role in the regulation of T-cell differentiation (Quintana 2013). The toxicity of the non-dioxin like PCBs is poorly understood but believed to be mediated through non-AhR mechanisms. In vitro, these PCBs have been shown to antagonize androgen receptor activation, affect estrogen receptor activation, inhibit gap junction communication and bind to transthyretin (Hamers et al. 2011). Also, neuronal toxicity through the Ryanodine receptors has been described (Wayman et al. 2012). OCPs including 1,1-bis-(4-chlorophenyl)-2,2-dichloroethene (p,p'-DDE), hexachlorobenzene (HCB) as well as the PBDEs, which are structurally similar to PCBs, are believed to be endocrine disruptors by their interference with different hormone systems (Karami-Mohajeri and Abdollahi 2011; Li et al. 2008; Vonderheide et al. 2008). Furthermore, negative effects of POPs may be related to induction of proinflammatory pathways (Karami-Mohajeri and Abdollahi 2011; Gauthier and Girard 2001).

Lipoproteins consist of an outer layer of phospholipids, proteins and free cholesterol filled with triglycerides and esterified cholesterol. Lipoproteins are classified into three main fractions depending on their density; very low-density, low-density and high-density lipoproteins (VLDL, LDL and HDL respectively). VLDL is synthesized in the liver and transports lipids to peripheral tissues. LDL arises from hydrolysis of VLDL and delivers cholesterol to the cells by receptor mediated endocytosis. HDL is responsible for the reversed cholesterol transport in which excess cholesterol is transported back to the liver for excretion into bile (Brewer 2012; Rosenson et al. 2012). High levels of LDL cholesterol (LDL-C) are 
considered a strong risk factor for future CVD, thereby being the rationale for cholesterol lowering therapies. HDL, on the other hand, has been shown to possess anti-inflammatory, anti-oxidative as well as anti-thrombogenic properties, which have led to the viewpoint of HDL being protective against CVD. In line, low levels of HDL cholesterol (HDL-C) is a risk factor for CVD (Barter 2011; Chapman et al. 2011). Many HDL functions are determined by the proteins in the particles. One such important protein is paraoxonase 1 (PON1), a calciumdependent esterase associated to HDL in the circulation (Sirivarasai et al. 2007). PON1 has been shown to provide HDL with anti-inflammatory properties, which includes hydrolyzing lipid peroxides in LDL and preventing foam cell formation in the vascular wall (Gupta et al. 2009; Précourt et al. 2011). PON1 has also been shown to hydrolyze several metabolites of organophosphate pesticides such as paraoxon, chlorpyrifon, oxon and diazoxon (Costa et al. 2005). Furthermore, reduced PON1 activity has been linked to CVD (Mackness et al. 2003), diabetes mellitus (Gupta et al. 2011) and cancer (Elkiran et al. 2007).

Early reports have shown that POPs can bind to lipoproteins (Becker and Gamble 1982; Maliwal and Guthrie 1982; Vomachka et al. 1983). However, beside a previous study showing that a large fraction of POPs are associated to LDL/VLDL and HDL in healthy individuals (Norén et al. 1999), little is known about the human lipoprotein distribution of POPs in vivo and how this relates to disease progress. The aims of the current study were 1) to assess the distribution of POPs in lipoprotein fractions and 2) to investigate if the distributions differ in healthy controls as compared to subjects with CVD or cancer and 3) to investigate whether the POP levels can influence the activity of HDL-associated PON1. 


\section{Method and Material}

\subsection{Study participants}

Blood samples were available from participants in a previous questionnaire-based epidemiological study. All study subjects were living in an area polluted by POPs and metals from long lasting local industrial activities, as confirmed by environmental measurements by local authorities. For all individuals, information about age, gender, diseases, medication, diet, smoking, occupational exposure and other life-style factors was available (Helmfrid et al. 2012). After exclusion of individuals with diseases other than cancer or CVD, the total number of subjects available for study was 78. Plasma samples from a subgroup $(\mathrm{n}=28)$ of non-smokers were used for POP measurement in lipoprotein fractions. Cancer and CVD cases were randomly selected. Cancer included subjects with hormone-related cancer, skin cancer or lymphoma. The healthy controls were selected so to represent the disease groups with respect to age and gender. Plasma samples covered the full range of sumPCB previously measured (2-10 ng/mL). Thirteen individuals had levels in the first and second quartile (2-4 $\mathrm{ng} / \mathrm{mL}, 4$ healthy, 4 with cancer and 7 with CVD) while 15 individuals had levels in the third and fourth quartile (5-10 ng/mL, 3 healthy, 4 with cancer and 8 with CVD) of the whole population. For arylesterase measurements, plasma from all 78 individuals was used. The clinical characteristics of selected samples are presented in Table 1 . The study was approved by the local ethics committee.

\subsection{Lipoprotein isolation}

Very low/low density lipoprotein (VLDL/LDL) and high density lipoprotein (HDL) were isolated from plasma with density ultracentrifugation as described before (Karlsson et al. 2005). To avoid POP interaction with the centrifuge tubes, polycarbonate instead of polyallomer tubes were used. In short, plasma were mixed with a sucrose and EDTA solution and over layered with a $\mathrm{KBr} / \mathrm{PBS}$ solution with the density $1.063 \mathrm{~g} / \mathrm{mL}$. Centrifugation was performed at $290000 \mathrm{~g}$ at $15^{\circ} \mathrm{C}$ for $4 \mathrm{~h}$ in a Beckman Coulter Ti 70.1 rotor. Lipoprotein fractions were aspirated and kept at $-20^{\circ} \mathrm{C}$ in dark glass bottles prior to analysis of POPs.

\subsection{Sample preparation and POP analysis}

Concentrations of 20 POPs were analyzed by a previously described method (Salihovic et al. 2012), with minor modifications. 14 PCB congeners (\#74, \#99, \#105, \#118, \#138, \#153, \#156, \#157, \#170, \#180, \#189, \#194, \#206 and \#209), 1 dioxin (octachlorodibenzo-p-dioxin,

OCDD), 4 OCPs (hexachlorobenzene, p,p'-DDE, cis-chlordane and trans-nonachlor) and 1 brominated flame retardant (bromodiphenylether \#47, BDE\#47) were investigated. Formic acid was used together with sonication to denature proteins in $0.5 \mathrm{~mL}$ of isolated LDL/VLDL or HDL fractions. Labeled ${ }^{13} \mathrm{C}$ internal standards were added to the samples before the POPs were extracted from lipoprotein fractions by solid-phase extraction (SPE) using Oasis ${ }^{\circledR}$ HLB single use cartridges $\left(6 \mathrm{~cm}_{3} / 150 \mathrm{mg}\right.$, Waters, Milford, MA, USA). The extracts were further purified with multi-layered acidified silica columns containing 56\% KOH silica gel, $40 \%$ $\mathrm{H}_{2} \mathrm{SO}_{4}$ silica gel and activated anhydrous $\mathrm{Na}_{2} \mathrm{SO}_{4}$. Concentrations of POPs were analyzed using high resolution gas chromatography/high resolution mass spectrometry (HRGC-HRMS, Waters, Milford, MA, US). 
Of all PCBs measured, 5 were dioxin-like and 9 were non-dioxin-like. The relative distribution of PCB congeners in the lipoprotein fractions compared to plasma was determined by the percentage proportion of a PCB congener in the lipoprotein fraction divided with the proportion in the plasma fraction. A ratio $>1$ indicates a greater relative amount of the PCB congener in the lipoprotein fraction than in the plasma.

\subsection{Paraoxonase-1 arylesterase activity in plasma}

The level of Paraoxonase-1 (PON1) arylesterase activity in plasma samples were determined similar to a previously described method (Richter et al. 2008). Plasma was diluted 1:40 in salt buffer (20 mM Tris-HCl, $1.0 \mathrm{mM} \mathrm{CaCl}_{2}, \mathrm{pH} \mathrm{8.0)}$ and $800 \mu \mathrm{L}$ of phenyl acetate solution (3.26 $\mathrm{mM}$ phenyl acetate in salt buffer) were mixed with $80 \mu \mathrm{L}$ diluted plasma. The absorbance of produced phenol was measured at $270 \mathrm{~nm}$ with $250 \mathrm{~nm}$ as background for $2 \mathrm{~min}$ in a DU 800 spectrophotometer (Beckman Coulter, Fullerton, CA, USA). The initial period when the reaction was linear were used for calculation of activity, expressed as U/mL, using an extinction coefficient of phenol of $1310 \mathrm{M}^{-1} \mathrm{~cm}^{1}$. Each sample was analyzed in triplicate.

\subsection{Statistical analysis}

Concentrations of POPs in subsets were statistically evaluated and compared by age-adjusted main effects ANOVA and post-hoc test Bonferroni using Statistica (StatSoft, Tulsa, OK, USA). A p-value of less than 0.05 was considered significant. Multivariate covariations between POPs, diseases, arylesterase activity and other life-style variables were analyzed by principal component analysis (PCA) with the nonlinear iterative partial least squares (NIPALS) algorithm in Statistica. Principal components (PCs) with eigenvalues greater than 1 (Kaiser Method) and occurring before the first kink (elbow) in the Scree plot (Cattels criteria) were included in the PCA. Correlations between relative concentrations of PCBs in lipoprotein versus plasma and number of chlorines in the PCB congeners as well as between sumPCB and arylesterase-activity were analyzed with Spearman and Pearson Correlation in SPPS (v17, IBM, NY, USA), respectively.

\section{Results}

\subsection{POP analyses in LDL/VLDL and HDL}

All 14 PCB congeners and two pesticides (p,p'-DDE and trans-nonachlor) were detected in LDL/VLDL from most of the individuals (Table 2). Likewise, most PCB congeners, p,p'DDE and trans-nonachlor were detected in the HDL of almost all individuals, although at lower concentrations than in LDL/VLDL. Of the PCBs, only congener \#74 and \#99 were less commonly detected (in $40 \%$ and $60 \%$ of the subjects, respectively). In contrast, cischlordane was only detected in LDL/VLDL of one individual but not in HDL. OCDD and BDE\#47 were not detected in either lipoprotein fraction in any individual. HCB was detected in LDL/VLDL (two of the controls, 7 subjects with cancer, and 12 subjects with CVD) and to a lower degree in HDL ( 1 control, 2 with cancer, 4 with CVD). The four non-dioxin-like PCB 
congeners PCB\#138, PCB\#153, PCB\#170 and PCB\#180 constituted approximately $80 \%$ of the total PCB concentration in both lipoprotein fractions.

As shown in Figure 1, the sumPCB concentrations were significantly higher in the cancer and CVD groups compared to the healthy controls. Overall, the concentrations of PCB congeners, p,p'-DDE and trans-nonachlor were about two-fold higher in the subjects with cancer or CVD compared to healthy individuals (Table 2). When compared to controls, subjects with cancer had significantly higher concentrations of PCB\#153, PCB\#170, PCB\#180, PCB\#209 in LDL/VLDL whereas PCB\#156, PCB\#153 and PCB\#209 were significantly higher in HDL. Individuals with CVD showed significantly higher concentrations of PCB\#156, PCB\#157, PCB\#180, PCB\#206 in LDL/VLDL compared to controls. In HDL, PCB\#138 and PCB\#153 were significantly higher compared to the controls. For the OCPs, only trans-nonachlor in LDL/VLDL from subjects with CVD was significantly higher compared to healthy controls. In comparison, the original plasma analysis showed no significant differences in the concentrations of individual POPs or sumPCB between the groups although there was a similar trend towards higher concentrations in subjects with cancer and CVD than controls (supplemental table 1).

The relative distribution of PCBs in lipoproteins increased, compared to plasma, with a higher number of chlorine substitutions (Figure 2). In line, a correlation was observed between the number of chlorine substitutions of the congeners studied and the relative distribution in LDL/VLDL and in HDL, ( $r=0.64 ; p<0.001$ and $r=0.61 ; p<0001$, respectively).

PCA showed that POP concentrations in LDL/VLDL were more associated with cancer whereas POPs in HDL were more associated with CVD (Figure 3). As also shown in the PCA plot, the concentrations of POPs in both lipoprotein fractions were associated with age and female gender. In the analyses, two principal components were retained, explaining $58 \%$ of the original variance.

\subsection{Paraoxonase 1 (PON1) activity}

No significant differences were found in levels of arylesterase activity in subjects with cancer and/or CVD as compared to healthy controls. However, in the larger sample $(n=78)$ there was significant lower arylesterase activity in individuals with highest sumPCB concentrations in plasma (fourth quartile) as compared to the subjects with lowest sumPCB concentrations (first quartile); $51.8 \pm 16.0$ vs $73.1 \pm 17.8 \mathrm{U} / \mathrm{mL}$ ( $\mathrm{p}<0.001$ after adjustment for smoking and age). Although less clear, also the second and third quartile showed lower activity $(60.3 \pm 14.2$ and $70.8 \pm 17.5 \mathrm{U} / \mathrm{mL}$, respectively) compared to the first quartile and there was a negative trend between the sumPCB quartiles and arylesterase activity, $r=-0.338(\mathrm{p}<0.01)$. Examining the subgroups, a significant negative correlation between sumPCB and PON1 activity were found in subjects with CVD (Figure 4), but not in subjects with cancer or in healthy individuals. In concordance, an association between decreased arylesterase activity, increased concentration of sumPCB in plasma and CVD was also seen in the PCA (Figure 5). In the analyses, two principal components were retained, explaining $30 \%$ of the original variance. 


\section{Discussion}

In the present study we show that plasma lipoprotein fractions in subjects with reported CVD or cancer contain higher concentrations of POPs compared to healthy individuals living in the same area. Interestingly, multivariate analysis indicated that high POP concentrations in HDL were more associated to CVD while high POP concentrations in LDL/VLDL were more associated to cancer. These observations suggest that the biological relevance of the binding of POPs to lipoprotein particles is more complex than merely a distribution of the lipophilic POPs to the cholesterol particles from the surrounding hydrophilic milieu in the blood. Therefore, it is likely that HDL and LDL are important routes for the distribution of these toxic compounds in the body that needs to be considered. At the same time, it is important to point out that this cross-sectional study does not allow conclusions regarding causality and we cannot exclude that the diseases or medications may affect the concentrations of POPs. However, no significant differences in POP concentrations were found when comparing the individuals with cancer that received cytostatic treatment with those that did not or when comparing individuals with CVD treated with anticoagulants, antihypertensive drugs and/or statins to subjects with CVD not receiving these drugs. Due to the low number of subjects, no analysis of subgroups, e.g. specific cancer types, was performed. Notably, four of the eight cases had hormone-related cancers that are suspected to be associated with POP exposure.

Fourteen PCB congeners and 3 pesticides were detected in HDL and LDL/VLDL. The concentrations were about three times higher in LDL/VLDL compared to HDL, consistent with previous results (Norén et al. 1999). In line with plasma analyses (Færch et al. 2012; Lind et al. 2012), the non-dioxin-like congeners PCB\#138, PCB\#153, PCB\#170 and PCB\#180 were found in the highest concentrations. However, compared to plasma, we found an enrichment of highly chlorinated PCBs, octa-, nona- and deca-chlorinated PCBs, in the lipoprotein fractions. Interestingly, the same congeners (PCB\#194, \#206 and \#209) have recently been shown to be associated with the presence of echolucent intima-media complex (Lind et al. 2012), which is a marker for a lipid-rich arterial wall and a suggested predictor for future CVD mortality (Wohlin et al. 2009).

In the multivariate model used (PCA with NIPALS algorithm) we included the factors age, POP concentrations of investigated fractions, sample groups and clinical parameters such as triglycerides and cholesterol. The model aims at simplifying complex datasets by creating principal components based on the variation of the input variables. These are then used to visualize and find systematic variations and how these relate to each other. The loading plot showed that the POP concentrations grouped together in two clusters indicating high levels of covariation. Interestingly, POPs in HDL were located relatively close to the CVD patients indicating a covariation between these variables, while POPs in LDL showed an association with the cancer group. These results indicate a link between POPs in HDL and CVD as well as between POPs in LDL and cancer. Such associations might be potentially important to understand why CVD and cancer are related to increased plasma concentrations of POPs (Engel et al. 2007; Hardell et al. 2006; Lind et al. 2012; Sergeev \& Carpenter 2010). In 
general, HDL is believed to have a protective role in CVD partly mediated through the reversed cholesterol transport in which HDL deliver excess cholesterol to the hepatocytes for further excretion. Through this action, HDL may participate in the clearance of POPs from the circulation. Besides, HDL probably has an important anti-inflammatory action in the circulation and the arterial wall through the anti-oxidant enzyme PON1 located on the HDL particle. In rats exposed to the dioxin-like congener PCB-126, increased expression and activity of PON1 have been described (Shen et al. 2012). In the present study, we found an inverse correlation between the sum of PCBs and PON1 activity in plasma among the subjects with CVD. These results indicate that PCBs may affect the activity of PON1 in HDL. Reduced PON1 activity is a described risk factor for CVD (Mackness et al. 2003) and may diminish the ability of HDL to neutralize oxidized products, such as oxidized LDL, in the vascular wall and increase the risk of atherosclerosis. Contrary to HDL, LDL delivers cholesterol to peripheral cells. Therefore, a transfer route of POPs via LDL-receptor mediated endocytosis is possible. Notably, tumor cells have an increased need for structural elements and are thereby known to up-regulate LDL receptors (Pires et al. 2012). These mechanisms may result in increased LDL-POP transport into the tumor cells. On the other hand, an in vitro study has suggested that LDL-receptors play a minor role in the cellular uptake of DDTlipoprotein complexes (Hjelmborg et al. 2008). Since POPs have been described to be carcinogenic (National Toxicology Program 2006), affecting gene expression (Mitra et al. 2012), be pro-inflammatory (Kim et al. 2012) and to cause oxidative stress (Abdollahi et al. 2004), they may, once inside the cells, contribute to the initiation of tumors as well as tumor progression. It is also possible that POPs may alter LDL function through effects on apolipoproteins (Arehart et al. 2004). Further studies are therefore needed to investigate the protein composition of both LDL and HDL in relation to POPs.

In conclusion, 14 PCB congeners and 3 pesticides were analyzed in HDL and LDL, and higher concentrations of POPs were found in lipoprotein fractions from individuals with CVD or cancer compared to healthy controls. We also found a negative correlation between PON1 arylesterase activity and the concentrations of PCB in plasma. These findings support the hypothesis that POPs are transported in the lipoprotein fractions and indicate that PCB can affect the HDL anti-oxidative function.

\section{Acknowledgements}

This study was supported by the Research Council of southeast Sweden (FORSS-235481). 


\section{References}

Abdollahi M, Ranjbar A, Shadnia S, Nikfar S, Rezaie A. Pesticides and oxidative stress: a review. Med Sci Monit 2004;10:RA141-147.

Arehart E, Giasson G, Walsh MT, Patterson H. Dioxin alters the human low-density and very low-density lipoprotein structure with evidence for specific quenching of Trp-48 in apolipoprotein C-II. Biochemistry 2004;43:8503-8509 DOI:10.1021/bi036190i.

Barter P. HDL-C: role as a risk modifier. Atheroscler Suppl 2011;12:267-270 DOI:10.1016/S1567-5688(11)70885-6.

Becker MM and Gamble W. Determination of the binding of 2,4,5,2',4',5'-hexachlorobiphenyl by low density lipoprotein and bovine serum albumin. J Toxicol Environ Health 1982;9:225-234 DOI:10.1080/15287398209530157.

Brewer HB. Clinical review: The evolving role of HDL in the treatment of high-risk patients with cardiovascular disease. J Clin Endocrinol Metab 2011;96:12461257 DOI:10.1210/jc.2010-0163.

Chapman J, Ginsberg HN, Amarenco P, Andreotti F, Boren J, Catapano AL et al. Triglyceride-rich lipoproteins and high-density lipoprotein cholesterol in patients at high risk of cardiovascular disease: evidence and guidance for management. Eur Heart J 2011;32:1345-1361 DOI:10.1093/eurheartj/ehr112.

Costa LG, Cole TB, Vitalone A, Furlong CE. Measurement of paraoxonase (PON1) status as a potential biomarker of susceptibility to organophosphate toxicity. Clin Chim Acta 2005;352:37-47 DOI:10.1016/j.ccen.2004.09.019.

Diamond ML, Melymuk L, Csiszar SA, Robson M. Estimation of PCB stocks, emissions, and urban fate: will our policies reduce concentrations and exposure? Environ Sci Technol 2010;44:2777-2783 DOI:10.1021/es9012036; 10.1021/es9012036.

Donato F, Magoni M, Bergonzi R, Scarcella C, Indelicato A, Carasi S et al. Exposure to polychlorinated biphenyls in residents near a chemical factory in Italy: the food chain as main source of contamination. Chemosphere 2006;64:1562-1572 DOI:10.1016/j.chemosphere.2005.11.057.

Elkiran ET, Mar N, Aygen B, Gursu F, Karaoglu A, Koca S. Serum paraoxonase and arylesterase activities in patients with lung cancer in a Turkish population. BMC Cancer 2007;7:48 DOI:10.1186/1471-2407-7-48.

Engel LS, Laden F, Andersen A, Strickland PT, Blair A, Needham LL et al. Polychlorinated biphenyl levels in peripheral blood and non-Hodgkin's lymphoma: a report from three cohorts. Cancer Res 2007;67:5545-5552 DOI:10.1158/0008-5472.CAN-06-3906.

Faerch K, Hojlund K, Vind BF, Vaag A, Dalgard C, Nielsen F et al. Increased serum concentrations of persistent organic pollutants among prediabetic individuals: potential role of altered substrate oxidation patterns. J Clin Endocrinol Metab 2012;97:E1705-1713

DOI:10.1210/jc.2012-1342. 
Gauthier M and Girard D. Activation of human neutrophils by chlordane: induction of superoxide production and phagocytosis but not chemotaxis or apoptosis. Hum Exp Toxicol 2001;20:229-235 .

Golden R and Kimbrough R. Weight of evidence evaluation of potential human cancer risks from exposure to polychlorinated biphenyls: an update based on studies published since 2003. Crit Rev Toxicol 2009;39:299-331 DOI:10.1080/10408440802291521.

Gupta N, Gill K, Singh S. Paraoxonases: structure, gene polymorphism \& role in coronary artery disease. Indian J Med Res 2009;130:361-368 .

Gupta N, Binukumar BK, Singh S, Sunkaria A, Kandimalla R, Bhansali A et al. Serum paraoxonase-1 (PON1) activities (PONase/AREase) and polymorphisms in patients with type 2 diabetes mellitus in a North-West Indian population. Gene 2011;487:88-95 DOI:10.1016/j.gene.2011.07.011

Hamers T, Kamstra JH, Cenijn PH, Pencikova K, Palkova L, Simeckova P et al. In vitro toxicity profiling of ultrapure non-dioxin-like polychlorinated biphenyl congeners and their relative toxic contribution to PCB mixtures in humans. Toxicol Sci 2011;121:88-100 DOI:10.1093/toxsci/kfr043.

Hardell L, Andersson SO, Carlberg M, Bohr L, van Bavel B, Lindstrom G et al. Adipose tissue concentrations of persistent organic pollutants and the risk of prostate cancer. J Occup Environ Med 2006;48:700-707 DOI:10.1097/01.jom.0000205989.46603.43.

Helmfrid I, Berglund M, Lofman O, Wingren G. Health effects and exposure to polychlorinated biphenyls (PCBs) and metals in a contaminated community. Environ Int 2012;44:53-58 DOI:10.1016/j.envint.2012.01.009.

Henry TR, DeVito MJ, Michael J. Non-dioxin-like PCBs: Effects and consideration in ecological risk assessment. 2003. Washington, DC: Ecological Risk Assessment Support Center, Office of Research and Development, U.S. Environmental Protection Agency.

Hjelmborg PS, Andreassen TK, Bonefeld-Jorgensen EC. Cellular uptake of lipoproteins and persistent organic compounds--an update and new data. Environ Res 2008;108:192-198 DOI:10.1016/j.envres.2008.07.019.

Hovander L, Linderholm L, Athanasiadou M, Athanassiadis I, Bignert A, Fangstrom B et al. Levels of PCBs and their metabolites in the serum of residents of a highly contaminated area in eastern Slovakia. Environ Sci Technol 2006;40:3696-3703

Karami-Mohajeri S and Abdollahi M. Toxic influence of organophosphate, carbamate, and organochlorine pesticides on cellular metabolism of lipids, proteins, and carbohydrates: a systematic review. Hum Exp Toxicol 2011;30:1119-1140 DOI:10.1177/0960327110388959.

Karlsson H, Leanderson P, Tagesson C, Lindahl M. Lipoproteomics II: mapping of proteins in high-density lipoprotein using two-dimensional gel electrophoresis and mass spectrometry. Proteomics 2005;5:1431-1445 DOI:10.1002/pmic.200401010.

Kim MJ, Pelloux V, Guyot E, Tordjman J, Bui LC, Chevallier A et al. Inflammatory pathway genes belong to major targets of persistent organic pollutants in adipose cells. Environ Health Perspect 2012;120:508-514 DOI:10.1289/ehp.1104282. 
Langer P, Kocan A, Tajtakova M, Petrik J, Chovancova J, Drobna B et al. Fish from industrially polluted freshwater as the main source of organochlorinated pollutants and increased frequency of thyroid disorders and dysglycemia. Chemosphere 2007;67:S379-385

DOI:10.1016/j.chemosphere.2006.05.132.

Lee DH, Steffes MW, Sjodin A, Jones RS, Needham LL, Jacobs DR. Low dose organochlorine pesticides and polychlorinated biphenyls predict obesity, dyslipidemia, and insulin resistance among people free of diabetes. PLoS One 2011;6:e15977 DOI:10.1371/journal.pone.0015977.

Li J, Li N, Ma M, Giesy JP, Wang Z. In vitro profiling of the endocrine disrupting potency of organochlorine pesticides. Toxicol Lett 2008;183:65-71

DOI:10.1016/j.toxlet.2008.10.002

Lind PM, van Bavel B, Salihovic S, Lind L. Circulating levels of persistent organic pollutants (POPs) and carotid atherosclerosis in the elderly. Environ Health Perspect 2012;120:38-43

DOI:10.1289/ehp.1103563.

Mackness B, Durrington P, McElduff P, Yarnell J, Azam N, Watt M et al. Low paraoxonase activity predicts coronary events in the Caerphilly Prospective Study. Circulation 2003;107:2775-2779 DOI:10.1161/01.CIR.0000070954.00271.13.

Maliwal BP and Guthrie FE. In vitro uptake and transfer of chlorinated hydrocarbons among human lipoproteins. J Lipid Res 1982;23:474-479 .

Mitra PS, Ghosh S, Zang S, Sonneborn D, Hertz-Picciotto I, Trnovec T et al. Analysis of the toxicogenomic effects of exposure to persistent organic pollutants (POPs) in Slovakian girls: correlations between gene expression and disease risk. Environ Int 2012;39:188-199

DOI:10.1016/j.envint.2011.09.003.

National Toxicology Program. NTP toxicology and carcinogenesis studies of 3,3',4,4',5 pentachlorobiphenyl (PCB 126) (CAS No. 57465-28-8) in female Harlan Sprague-Dawley rats (Gavage Studies). Natl Toxicol Program Tech Rep Ser 2006;(520):4-246 .

Norén K, Weistrand C, Karpe F. Distribution of PCB congeners, DDE, hexachlorobenzene, and methylsulfonyl metabolites of PCB and DDE among various fractions of human blood plasma. Arch Environ Contam Toxicol 1999;37:408-414 .

Pires LA, Hegg R, Freitas FR, Tavares ER, Almeida CP, Baracat EC et al. Effect of neoadjuvant chemotherapy on low-density lipoprotein (LDL) receptor and LDL receptor-related protein 1 (LRP-1) receptor in locally advanced breast cancer. Braz J Med Biol Res 2012;45:557-564 .

Precourt LP, Amre D, Denis MC, Lavoie JC, Delvin E, Seidman E et al. The three-gene paraoxonase family: physiologic roles, actions and regulation. Atherosclerosis 2011;214:20-36 DOI:10.1016/j.atherosclerosis.2010.08.076.

Quintana FJ. The aryl hydrocarbon receptor: a molecular pathway for the environmental control of the immune response. Immunology 2013;138:183-189 DOI:10.1111/imm.12046.

Richter RJ, Jarvik GP, Furlong CE. Determination of paraoxonase 1 status without the use of toxic organophosphate substrates. Circ Cardiovasc Genet 2008;1:147-152 DOI:10.1161/CIRCGENETICS.108.811638. 
Rosenson RS, Brewer HB, Davidson WS, Fayad ZA, Fuster V, Goldstein J et al. Cholesterol efflux and atheroprotection: advancing the concept of reverse cholesterol transport. Circulation 2012;125:1905-1919

DOI:10.1161/CIRCULATIONAHA.111.066589.

Salihovic S, Mattioli L, Lindstrom G, Lind L, Lind PM, van Bavel B. A rapid method for screening of the Stockholm Convention POPs in small amounts of human plasma using SPE and HRGC/HRMS. Chemosphere 2012;86:747-753 DOI:10.1016/j.chemosphere.2011.11.006.

Sergeev AV and Carpenter DO. Exposure to Persistent Organic Pollutants Increases Hospitalization Rates for Myocardial Infarction with Comorbid Hypertension. Prim Prev Insights 2010;2:1-9 DOI:10.4137/PPRI.S4332.

Shen H, Robertson LW, Ludewig G. Regulation of paraoxonase 1 (PON1) in PCB 126 exposed male Sprague Dawley rats. Toxicol Lett 2012;209:291-298 DOI:10.1016/j.toxlet.2012.01.003.

Sirivarasai J, Kaojarern S, Yoovathaworn K, Sura T. Paraoxonase (PON1) polymorphism and activity as the determinants of sensitivity to organophosphates in human subjects. Chem Biol Interact 2007;168:184-192 DOI:10.1016/j.cbi.2007.04.006.

Vomachka MS, Vodicnik MJ, Lech JJ. Characteristics of 2,4,5,2',4',5'-hexachlorobiphenyl distribution among lipoproteins in vitro. Toxicol Appl Pharmacol 1983;70:350 361 .

Vonderheide AP, Mueller KE, Meija J, Welsh GL. Polybrominated diphenyl ethers: causes for concern and knowledge gaps regarding environmental distribution, fate and toxicity. Sci Total Environ 2008;400:425-436 DOI:10.1016/j.scitotenv.2008.05.003.

Wayman GA, Yang D, Bose DD, Lesiak A, Ledoux V, Bruun D et al. PCB-95 promotes dendritic growth via ryanodine receptor-dependent mechanisms. Environ Health Perspect 2012;120:997-1002 DOI:10.1289/ehp.1104832.

Wikoff D, Fitzgerald L, Birnbaum L. Persistent organic pollutants: An overview, in: Schecter A. (Ed.), Dioxins and health: Including Other Persistent Organic Pollutants and Endocrine Disruptors, third edition. John Wiley \& Sons, Inc., New Jersey, 2012:1-35 DOI: $10.1002 / 9781118184141 . c h 1$

Wohlin M, Sundstrom J, Andren B, Larsson A, Lind L. An echolucent carotid artery intima media complex is a new and independent predictor of mortality in an elderly male cohort. Atherosclerosis 2009;205:486-491

DOI:10.1016/j.atherosclerosis.2009.01.032. 
Table 1 - Clinical characteristics of study subjects

\begin{tabular}{|c|c|c|c|c|}
\hline & Healthy controls & Cancer & CVD & Cancer \& CVD \\
\hline \multicolumn{5}{|c|}{ Population $(n=78)$} \\
\hline $\mathbf{N}$ & 14 & 18 & 28 & 18 \\
\hline Age (range) & $24-79$ & $40-89$ & $41-87$ & $55-90$ \\
\hline Gender (Male/Female) & $4 / 10$ & $7 / 11$ & $12 / 16$ & $10 / 8$ \\
\hline Smokers (N) & 2 & 3 & 1 & 4 \\
\hline BMI (mean \pm SD) & $27.0 \pm 3.9$ & $25.9 \pm 4.8$ & $27.4 \pm 4.4$ & $27.6 \pm 3.9$ \\
\hline Triglycerides mmol/L (mean \pm SD) & $1.6 \pm 0.7$ & $1.6 \pm 0.7$ & $1.7 \pm 0.5$ & $1.9 \pm 0.9$ \\
\hline Total cholesterol mmol/L (mean \pm SD) & $5.9 \pm 1.1$ & $5.9 \pm 1.2$ & $5.2 \pm 1.1$ & $4.9 \pm 1.1$ \\
\hline \multicolumn{5}{|c|}{ Subpopulation $(n=28)$} \\
\hline $\mathbf{N}$ & 7 & 6 & 13 & 2 \\
\hline Age (range) & $41-79$ & $52-89$ & $54-87$ & $68-86$ \\
\hline Gender (Male/Female) & $3 / 4$ & $2 / 4$ & $7 / 6$ & $1 / 1$ \\
\hline Smokers (N) & 0 & 0 & 0 & 0 \\
\hline BMI (mean \pm SD) & $29.0 \pm 2.3$ & $25.2 \pm 3.9$ & $26.9 \pm 4.5$ & $23.9 \pm 0.4$ \\
\hline Triglycerides mmol/L $($ mean \pm SD) & $2.0 \pm 0.6$ & $1.3 \pm 0.5$ & $1.8 \pm 0.5$ & $1.1 \pm 0,1$ \\
\hline Total cholesterol mmol/L $($ mean \pm SD $)$ & $6.1 \pm 1.0$ & $6.8 \pm 1.3$ & $5.2 \pm 1.0$ & $4.9 \pm 1.1$ \\
\hline
\end{tabular}


Table 2. POP concentrations in LDL/VLDL and HDL of healthy controls, subjects with cancer and subjects with cardiovascular disease.

\begin{tabular}{|c|c|c|c|c|c|c|c|}
\hline $\begin{array}{c}\text { Mean +- SD } \\
(\mathrm{pg} / \mathrm{mL})\end{array}$ & LOD & $\begin{array}{c}\text { Controls } \\
n=7\end{array}$ & $\begin{array}{c}\text { Cancer } \\
n=8\end{array}$ & $\begin{array}{c}\text { Cardiovascular } \\
\text { disease } \\
n=15\end{array}$ & $\begin{array}{c}\text { Controls } \\
n=7\end{array}$ & $\begin{array}{c}\text { Cancer } \\
n=8\end{array}$ & $\begin{array}{c}\text { Cardiovascular } \\
\text { disease } \\
n=15\end{array}$ \\
\hline \multicolumn{8}{|c|}{ Dioxin-like PCB congeners } \\
\hline PCB\#105 ${ }^{\mathrm{a}}$ & 1.4 & $3.9 \pm 2.4(6)$ & $7.5 \pm 7.8$ & $7.7 \pm 5.5$ & $1.7 \pm 2.5(3)$ & $1.6 \pm 1.7(5)$ & $2.6 \pm 2.4(11)$ \\
\hline PCB\#118 ${ }^{\mathrm{a}}$ & 5.0 & $17.2 \pm 7.1$ & $30.8 \pm 34.0$ & $29.6 \pm 18.9$ & $6.2 \pm 7.8(4)$ & $9.9 \pm 8.6(7)$ & $11.8 \pm 7.4$ \\
\hline PCB\#156 & 1.2 & $28.3 \pm 21.1$ & $53.8 \pm 30.0$ & $46.8 * \pm 23.2$ & $10.0 \pm 7.6$ & $17.0 * \pm 7.6$ & $16.4 \pm 8.1$ \\
\hline PCB\#157 ${ }^{\mathrm{a}}$ & 0.7 & $4.9 \pm 3.7$ & $15.8 \pm 14.5$ & $8.11 * \pm 4.0$ & $1.3 \pm 0.9(6)$ & $2.0 \pm 1.2$ & $2.2 \pm 1.2(14)$ \\
\hline PCB\#189 ${ }^{\mathrm{a}}$ & 0.5 & $4.5 \pm 4.1(6)$ & $4.8 \pm 3.7(7)$ & $6.0 \pm 3.5(14)$ & $0.7 \pm 1.1(3)$ & $1.7 \pm 1.5$ & $1.3 \pm 1.2(13)$ \\
\hline \multicolumn{8}{|c|}{ Non-dioxin-like PCB congeners } \\
\hline PCB\#74 ${ }^{\mathrm{a}}$ & 8.8 & $11.2 \pm 6.2(6)$ & $26.0 \pm 31.7(6)$ & $19.3 \pm 10.8(14)$ & $1.4 \pm 3.7(1)$ & $7.6 \pm 9.7(4)$ & $6.8 \pm 7.2(8)$ \\
\hline PCB\#99 ${ }^{a}$ & 8.4 & $14.6 \pm 4.6$ & $22.4 \pm 9.2$ & $27.3 \pm 16.5$ & $3.0 \pm 5.3(2)$ & $7.4 \pm 6.2(5)$ & $10.3 \pm 9.1(11)$ \\
\hline PCB\#138 & 7.7 & $126.0 \pm 71.5$ & $205.5 \pm 91.1$ & $222.5 \pm 137.5$ & $39.0 \pm 19.6$ & $56.8 \pm 22.6$ & $72.2 * \pm 39.0$ \\
\hline PCB\#153 & 9.4 & $164.2 \pm 100.5$ & $283.7 * \pm 128.0$ & $264.8 \pm 152.6$ & $52.4 \pm 30.5$ & $77.3 * \pm 28.2$ & $84.3 * \pm 38.8$ \\
\hline PCB\#170 & 2.3 & $105.3 \pm 67.9$ & $180.2 * \pm 75.1$ & $156.3 \pm 70.9$ & $34.2 \pm 23.7$ & $51.7 \pm 20.4$ & $52.8 \pm 24.0$ \\
\hline PCB\#180 & 4.9 & $143.3 \pm 3$ & $277.1 * \pm 118.7$ & $227.7 * \pm 100.5$ & $41.4 \pm 32.4$ & $63.4 \pm 32.4$ & $62.0 \pm 28.2$ \\
\hline PCB\#194 & 0.7 & $30.0 \pm 23.9$ & $54.0 \pm 24.6$ & $43.0 \pm 14.5$ & $10.3 \pm 8.6$ & $14.7 \pm 7.4$ & $14.7 \pm 6.7$ \\
\hline PCB\#206 & 0.6 & $6.0 \pm 3.2$ & $10.9 \pm 5.3$ & $9.27 * \pm 2.9$ & $2.1 \pm 1.5$ & $2.7 \pm 1.2$ & $3.0 \pm 1.4$ \\
\hline PCB\#209 & 1.1 & $8.5 \pm 5.7$ & $14.5 * \pm 6.2$ & $12.4 \pm 4.2$ & $3.1 \pm 1.5$ & $4.9 * \pm 1.7$ & $4.6 \pm 2.2$ \\
\hline \multicolumn{8}{|c|}{ Dioxins } \\
\hline OCDD & 2.1 & $<\mathrm{LOD}$ & $<\mathrm{LOD}$ & $<\mathrm{LOD}$ & $<\mathrm{LOD}$ & $<\mathrm{LOD}$ & $<\mathrm{LOD}$ \\
\hline \multicolumn{8}{|c|}{ Organochlorine pesticides } \\
\hline $\mathrm{HCB}^{\mathrm{a}}$ & 111.5 & $36.1 \pm 61.7(2)$ & $116.6 \pm 55.9(7)$ & $123.0 \pm 56.3(12)$ & $20.8 \pm 55.0(1)$ & $31.0 \pm 57.5(2)$ & $41.2 \pm 63.2(4)$ \\
\hline Cis-Chlordane $^{\text {a }}$ & 5.4 & $<\mathrm{LOD}$ & $1.3 \pm 3.7(1)$ & $<\mathrm{LOD}$ & $<\mathrm{LOD}$ & $<\mathrm{LOD}$ & $<\mathrm{LOD}$ \\
\hline $\begin{array}{c}\text { Trans- } \\
\text { nonachlor }^{a}\end{array}$ & 5.1 & $23.1 \pm 27.6(6)$ & $49.4 \pm 40.5$ & $53.5 * \pm 30.0$ & $9.0 \pm 15.2(3)$ & $16.0 \pm 10.4$ & $21.3 \pm 13.4$ \\
\hline p,p'-DDE & 4.9 & $118.3 \pm 52.1$ & $232.7 \pm 200.8$ & $306.8 \pm 304$ & $33.1 \pm 14.1$ & $61.1 \pm 45.2$ & $78.3 \pm 63.5$ \\
\hline \multicolumn{8}{|c|}{ Brominated flame retardant } \\
\hline BDE\#47 & 11.7 & $<\mathrm{LOD}$ & $<\mathrm{LOD}$ & $<\mathrm{LOD}$ & $<\mathrm{LOD}$ & $<\mathrm{LOD}$ & $<\mathrm{LOD}$ \\
\hline
\end{tabular}

LOD = Limit of detection, LDL = Low-density lipoprotein, VLDL = Very low-density lipoprotein, HDL = Highdensity lipoprotein

${ }^{\text {a }}$ Not detected in all individuals, parentheses state number of individuals with detectable concentrations

$*=p<0.05$ compared to healthy controls as found with age-adjusted main effects ANOVA. 


\section{Figures}

Figure 1

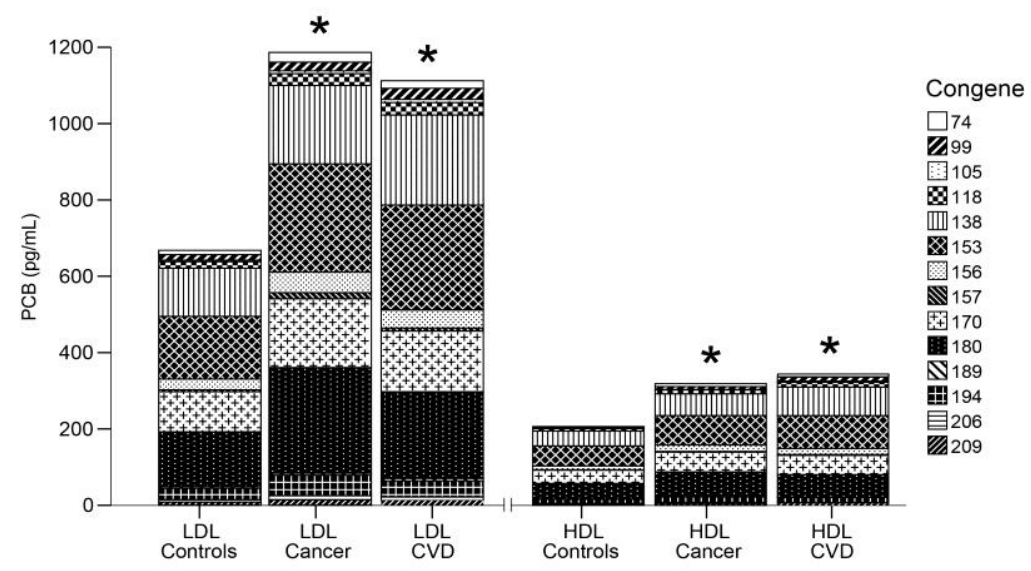

Figure 1. Comparison of PCB in controls, individuals with cancer and individuals with CVD. Mean of each congener is indicated within the bar and the total bar represents the mean of the sumPCB. * indicates p $<0.05$ compared to healthy controls in respective fraction as determined by age-adjusted main effects ANOVA.

\section{Figure 2}

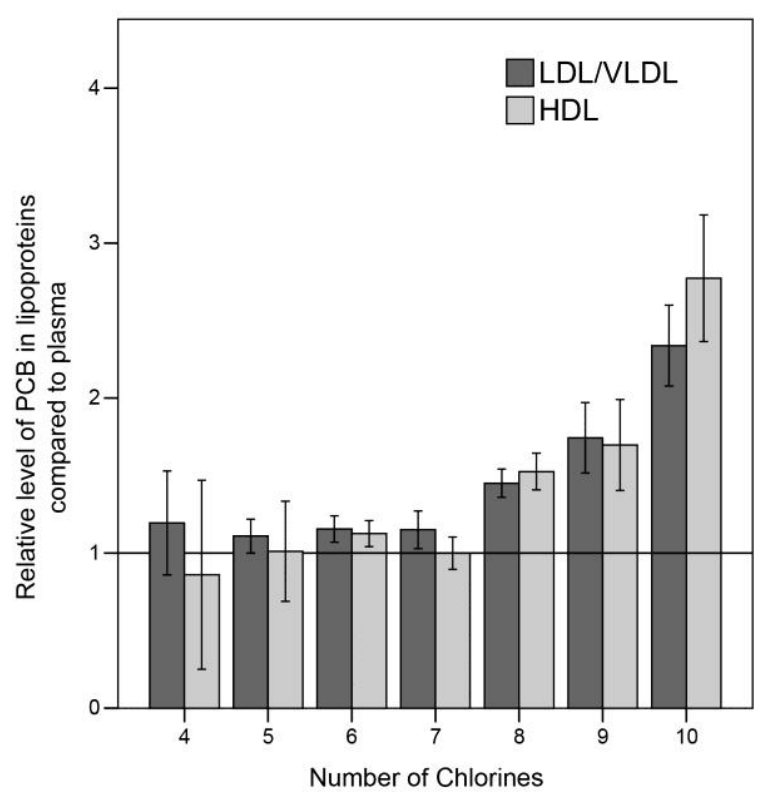

Figure 2. The mean relative distribution of PCB congeners in LDL/VLDL and HDL compared to plasma in relation to their number of chlorine atoms. Values are mean $\pm 99 \% \mathrm{CI}$. 


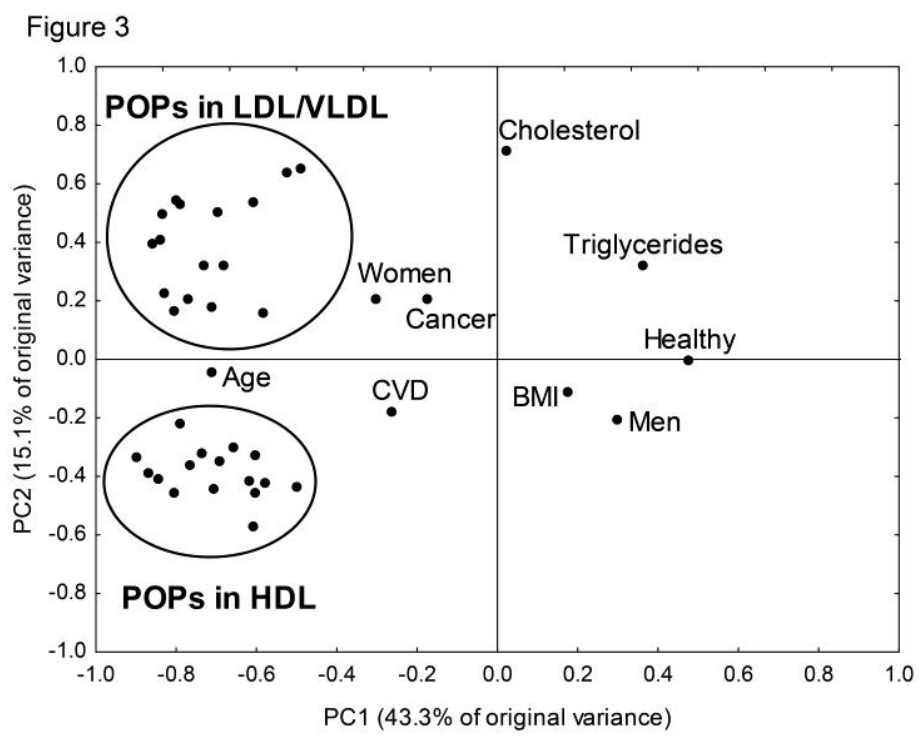

Figure 3. Principal Component Analysis loading plot of the covariation between POPs in LDL/VLDL, HDL, disease state, age, gender, BMI, cholesterol and triglycerides. The $\mathrm{x}$ - and y-axes represent the PC1 and PC2 loading scores, respectively. Principal component 1 (PC1) explained 43.3\% while PC2 explained $15.1 \%$ of the variation. Groups of POPs in LDL/VLDL and HDL are marked.

\section{Figure 4}

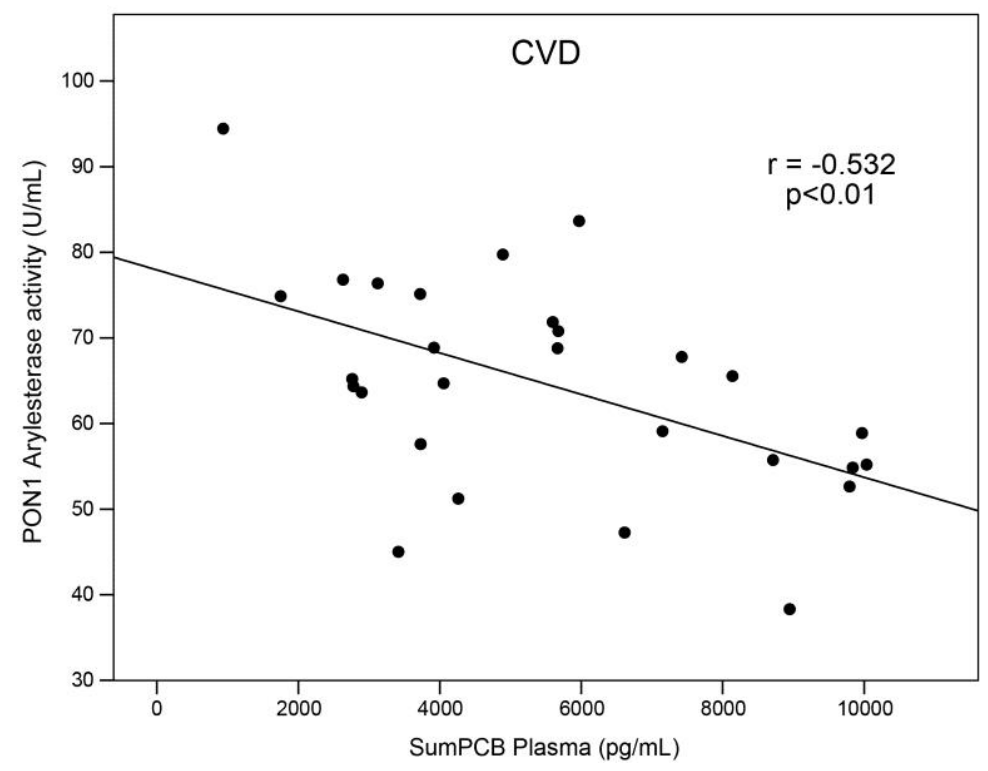

Figure 4. Inversed correlation between sumPCB in plasma and arylesterase activity in subjects with CVD $(n=28)$. 


\section{Figure 5}

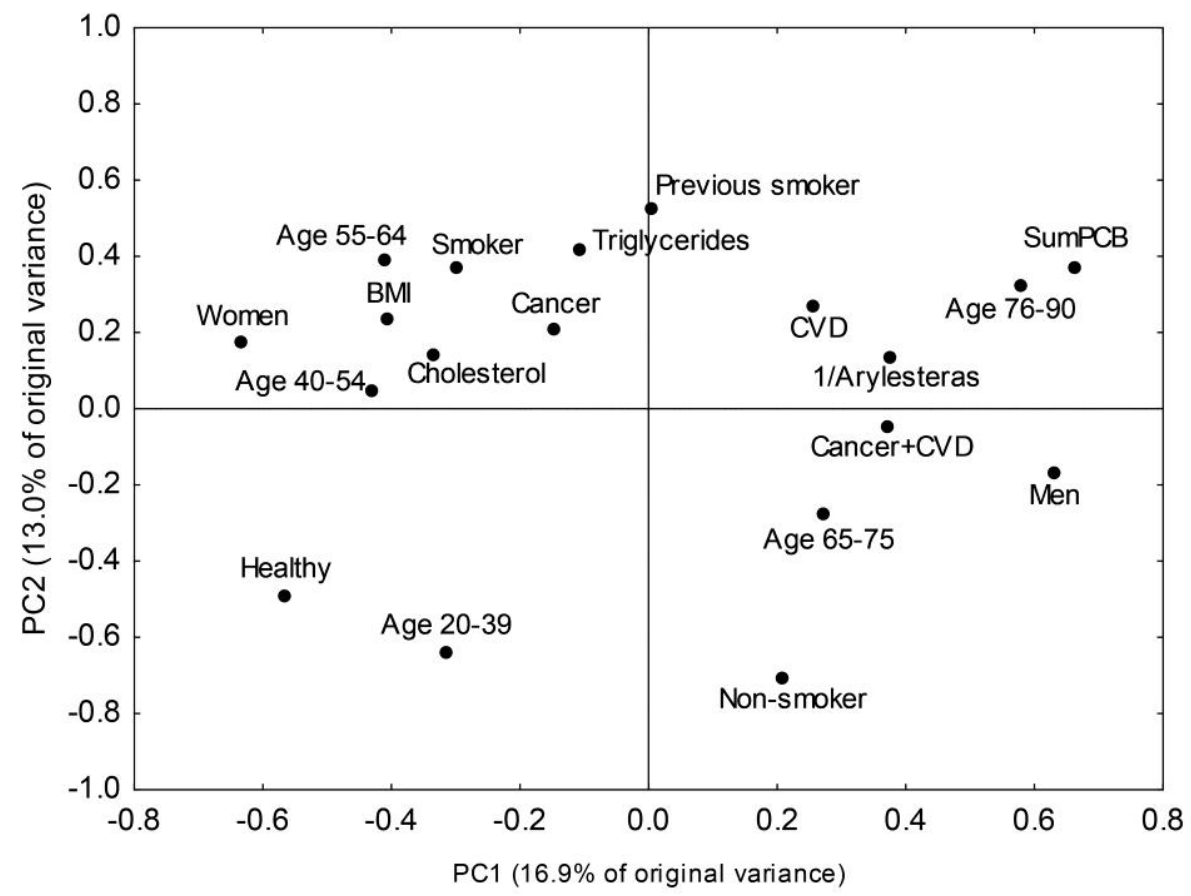

Figure 5. Principal Component Analysis loading plot of the covariation between inverted arylesterase activity in plasma, sumPCB in plasma, age groups, gender, disease states, smoking status, BMI, cholesterol and triglycerides. The $\mathrm{x}$ - and $\mathrm{y}$-axes represent the $\mathrm{PC} 1$ and $\mathrm{PC} 2$ loading scores, respectively. Principal component 1 (PC1) explained $16.9 \%$ while PC2 explained $13.0 \%$ of the variation. 


\section{Supplementary table 1. Plasma POP concentrations.}

\begin{tabular}{|c|c|c|c|c|}
\hline & & \multicolumn{3}{|c|}{ Plasma } \\
\hline Mean +- SD $(\mathrm{pg} / \mathrm{mL})$ & LOD & $\begin{array}{c}\text { Controls } \\
n=7\end{array}$ & $\begin{array}{c}\text { Cancer } \\
n=8\end{array}$ & $\begin{array}{c}\text { Cardiovascular } \\
\text { disease } \\
n=15\end{array}$ \\
\hline \multicolumn{5}{|c|}{ Dioxin-like PCB congeners } \\
\hline PCB\#105 & 5.3 & $27.0 \pm 16.0$ & $38.1 \pm 44.9$ & $47.1 \pm 40.1$ \\
\hline PCB\#118 & 17.1 & $134.4 \pm 65.1$ & $209.0 \pm 243.5$ & $219.8 \pm 187.4$ \\
\hline PCB\#156 & 7.8 & $146.6 \pm 66.9$ & $190.9 \pm 96.3$ & $177.3 \pm 69.6$ \\
\hline PCB\#157 & 1.1 & $24.1 \pm 10.5$ & $31.4 \pm 19.3$ & $31.4 \pm 14.9$ \\
\hline PCB\#189 & 0.9 & $20.5 \pm 10.8$ & $23.0 \pm 10.4$ & $24.9 \pm 10.6$ \\
\hline \multicolumn{5}{|c|}{ Non-dioxin-like PCB congeners } \\
\hline PCB\#74 & 6.4 & $56.6 \pm 22.1$ & $129.6 \pm 182.0$ & $92.2 \pm 77.7$ \\
\hline PCB\#99 & 11.2 & $67.3 \pm 26.9$ & $76.6 \pm 48.2$ & $101.9 \pm 66.3$ \\
\hline PCB\#138 & \begin{tabular}{|l|}
107.3 \\
\end{tabular} & $834.1 \pm 288.2$ & $1086.8 \pm 549.7$ & $1192.3 \pm 656.3$ \\
\hline PCB\#153 & 85.3 & $1213.7 \pm 426.3$ & $1481.8 \pm 791.3$ & $1635 . \pm 807.9$ \\
\hline PCB\#170 & 28.4 & $492.9 \pm 206.1$ & $585.7 \pm 240.3$ & $592.8 \pm 219.5$ \\
\hline PCB\#180 & 46.5 & $1054.1 \pm 447.7$ & $1315.2 \pm 529.3$ & $1317.1 \pm 479.9$ \\
\hline PCB\#194 & 4 & $128.9 \pm 63.9$ & $158.0 \pm 60.0$ & $154.7 \pm 47.0$ \\
\hline PCB\#206 & 1.3 & $25.1 \pm 11.5$ & $25.4 \pm 9.3$ & $30.1 \pm 11.6$ \\
\hline PCB\#209 & 1.1 & $21.9 \pm 9.0$ & $30.1 \pm 12.7$ & $29.8 \pm 12.7$ \\
\hline \multicolumn{5}{|c|}{ Dioxins } \\
\hline OCDD $^{\mathrm{a}}$ & 2.2 & $1.6 \pm 2.0(3)$ & $2.3 \pm 4.5(3)$ & $0.4 \pm 1.0(2)$ \\
\hline \multicolumn{5}{|c|}{ Organochlorine pesticides } \\
\hline $\mathrm{HCB}^{\mathrm{a}}$ & 93.4 & $164.7 \pm 45.1$ & $246.3 \pm 112.3$ & $173.8 \pm 124.9(12)$ \\
\hline Cis-Chlordane $^{\mathrm{a}}$ & 2.6 & $1.3 \pm 1.6(3)$ & $0.8 \pm 1.4(2)$ & $0.9 \pm 1.5(4)$ \\
\hline Trans-nonachlor & 3.5 & $100.7 \pm 59.0$ & $110.7 \pm 96.7$ & $161.8 \pm 88.2$ \\
\hline p,p'-DDE & 8.3 & $1347.7 \pm 945.3$ & $2653.4 \pm 2386.1$ & $3756.7 \pm 3173.7$ \\
\hline \multicolumn{5}{|c|}{ Brominated flame retardant } \\
\hline $\mathrm{BDE} \# 47^{\mathrm{a}}$ & 6.7 & $9.3 \pm 13.1(4)$ & $5.7 \pm 7.0(4)$ & $9.6 \pm 10.8(9)$ \\
\hline
\end{tabular}

LOD $=$ Limit of detection

${ }^{a}$ Not detected in all individuals, parentheses state number of individuals with detectable concentrations No significant differences between healthy controls and cancer or CVD found with age-adjusted main effects ANOVA. 